\title{
Transcriptome Analysis of Early Defenses in Rice against Fusarium fujikuroi
}

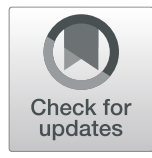

\author{
An-Po Cheng ${ }^{1 \dagger}$, Szu-Yu Chen ${ }^{1+}$, Ming-Hsin Lai ${ }^{2}$, Dong-Hong Wu ${ }^{2,3}$, Shih-Shun Lin ${ }^{4}$, Chieh-Yi Chen ${ }^{1}$ and \\ Chia-Lin Chung ${ }^{1 *}$ (i)
}

\begin{abstract}
Background: Bakanae is a seedborne disease caused by Fusarium fujikuroi. Rice seedlings emerging from infected seeds can show diverse symptoms such as elongated and slender stem and leaves, pale coloring, a large leaf angle, stunted growth and even death. Little is known about rice defense mechanisms at early stages of disease development.
\end{abstract}

Results: This study focused on investigating early defenses against $F$. fujikuroi in a susceptible cultivar, Zerawchanica karatals (ZK), and a resistant cultivar, Tainung 67 (TNG67). Quantitative PCR revealed that $F$. fujikuroi colonizes the root and stem but not leaf tissues. Illumina sequencing was conducted to analyze the stem transcriptomes of $F$. fujikuroi-inoculated and mock-inoculated ZK and TNG67 plants collected at 7 days post inoculation (dpi). More differentially expressed genes (DEGs) were identified in ZK $(n=169)$ than TNG67 $(n=118)$, and gene ontology terms related to transcription factor activity and phosphorylation were specifically enriched in ZK DEGs. Among the complex phytohormone biosynthesis and signaling pathways, only DEGs involved in the jasmonic acid (JA) signaling pathway were identified. Fourteen DEGs encoding pattern-recognition receptors, transcription factors, and JA signaling pathway components were validated by performing quantitative reverse transcription PCR analysis of individual plants. Significant repression of jasmonate ZIM-domain (JAZ) genes (OsJAZ9, OsJAZ10, and OsJAZ13) at 3 $\mathrm{dpi}$ and $7 \mathrm{dpi}$ in both cultivars, indicated the activation of JA signaling during early interactions between rice and $F$. fujikuroi. Differential expression was not detected for salicylic acid marker genes encoding phenylalanine ammonialyase 1 and non-expressor of pathogenesis-related genes 1. Moreover, while MeJA did not affect the viability of $F$. fujikuroi, MeJA treatment of rice seeds (prior to or after inoculation) alleviated and delayed bakanae disease development in susceptible ZK.

Conclusions: Different from previous transcriptome studies, which analyzed the leaves of infected plants, this study provides insights into defense-related gene expression patterns in F. fujikuroi-colonized rice stem tissues. Twelve out of the 14 selected DEGs were for the first time shown to be associated with disease resistance, and JAmediated resistance was identified as a crucial component of rice defense against F. fujikuroi. Detailed mechanisms underlying the JA-mediated bakanae resistance and the novel defense-related DEGs are worthy of further investigation.

Keywords: Fusarium fujikuroi, Transcriptome, Jasmonic acid, OsJAZ, XIAO, OsWRKY, OsERF

\footnotetext{
* Correspondence: clchung@ntu.edu.tw

${ }^{\dagger}$ An-Po Cheng and Szu-Yu Chen contributed equally to this work.

'Department of Plant Pathology and Microbiology, National Taiwan

University, No. 1, Sec. 4, Roosevelt Rd, Taipei City 10617, Taiwan

Full list of author information is available at the end of the article
}

\section{Springer Open}

(c) The Author(s). 2021 Open Access This article is licensed under a Creative Commons Attribution 4.0 International License, which permits use, sharing, adaptation, distribution and reproduction in any medium or format, as long as you give appropriate credit to the original author(s) and the source, provide a link to the Creative Commons licence, and indicate if changes were made. The images or other third party material in this article are included in the article's Creative Commons licence, unless indicated otherwise in a credit line to the material. If material is not included in the article's Creative Commons licence and your intended use is not permitted by statutory regulation or exceeds the permitted use, you will need to obtain permission directly from the copyright holder. To view a copy of this licence, visit http://creativecommons.org/licenses/by/4.0/. 


\section{Background}

Bakanae disease, caused by the heterothallic ascomycete fungus Fusarium fujikuroi Nirenberg, has become a threat to rice quality and yield in recent years. Many studies from Asian countries such as Bangladesh, India, South Korea, Pakistan, and Taiwan have reported the increasing incidence and severity of bakanae disease (Khan et al. 2000; Chu et al. 2010; Haq et al. 2010; Gupta et al. 2015; Kim et al. 2015). F. fujikuroi is a seed-borne pathogen that can infect rice panicles at the flowering stage (Ou 1985). Rice seedlings emerging from infected seeds can show diverse symptoms such as elongated and slender stem and leaves, pale coloring, a large leaf angle, stunted growth and even death. The conventional disease management strategy for bakanae disease is seed disinfection using fungicides. However, F. fujikuroi isolates resistant to benzimidazole, prochloraz, or tebuconazole have been reported (Chen et al. 2014; Kim et al. 2010; Chen et al. 2016). Because bakanae disease is becoming a serious threat to rice production, it is crucial to develop new control measures from different perspectives.

Bakanae resistance has been explored by large-scale screening of rice germplasm and quantitative trait locus (QTL) mapping. Research groups in India (Fiyaz et al. 2014), Korea (Kim et al. 2014), and Taiwan (Chen et al. 2019) used high-throughput inoculation methods to screen for resistant materials from 92, 500, and 231 diverse rice varieties, respectively. A total of 28 QTLs for bakanae resistance were mapped on rice chromosomes 1, 3, 4, 6, 8, 9, 10 and 11 (Volante et al. 2017; Fiyaz et al. 2016; Lee et al. 2018; Cheon et al. 2019; Ji et al. 2018a; Hur et al. 2015; Lee et al. 2019; Kang et al. 2019; Yang et al. 2006; Chen et al. 2019). Chromosome 1, where 13 QTLs are located, appears to be particularly important. Using four different bi-parental populations and rice diversity panel 1 (RDP1) (Cheon et al. 2019; Ji et al. 2018a; Hur et al. 2015; Lee et al. 2019; Fiyaz et al. 2016; Chen et al. 2019), co-localized QTLs were fine-mapped to a region (21.36-24.37 $\mathrm{Mb}$ on chromosome 1) crucial for bakanae resistance. Although QTLs have been associated with mortality rate, disease incidence, disease severity, and F. fujikuroi colonization, no causal genes have been cloned and functionally characterized.

Rice responses to F. fujikuroi have been investigated in two transcriptome analyses (Ji et al. 2016; Matić et al. 2016). Ji et al. (2016) examined the RNA from the leaves of a moderately resistant cultivar, $93-11$, and a susceptible cultivar, Nipponbare, at 7 days after treatment. Upon infection by F. fujikuroi, three WRKYs (OsWRKY107, OsWRKY13 and OsWRKY71), a wall-associated kinase (OsWAK112d), and two mitogen-activated protein kinase kinase kinase (MAP3K.4 and MAP3K.5) genes were upregulated in resistant 93-11, and five pollen Ole e I (POEI) genes (POEI11 to POEI15), which are known to be involved in the response to abiotic stress, were greatly induced in susceptible Nipponbare. It was also found that gene ontology (GO) terms related to reactive oxygen species generation and detoxification were enriched in both 93-11 and Nipponbare. Using another resistant cultivar, Selenio, and susceptible cultivar, Dorella, Matić et al. (2016) studied the transcriptomes of rice leaves at 7 and 21 days post inoculation (dpi). In general, F. fujikuroi infection induced the expression of glycoside hydrolases, MAPKs, and WRKYs in resistant Selenio, but caused upregulation of chitinases and down-regulation of MAPKs and WRKYs in susceptible Dorella at $21 \mathrm{dpi}$.

Phytohormones and phytoalexins have been implicated in bakanae resistance. In the study by Matić et al. (2016), the GO term "jasmonic acid biosynthetic process" was specifically enriched in genes differentially expressed upon F. fujikuroi infection in resistant cultivar Selenio, whereas the GO terms "response to salicylic acid stimulus" and "gibberellin metabolic process" were specifically enriched in genes differentially expressed in susceptible Dorella at $21 \mathrm{dpi}$. By quantifying phytohormones and phytoalexins in rice leaves and culms using HPLC-MS/MS, Siciliano et al. (2015) found that inoculation of $F$. fujikuroi induced the accumulation of gibberellin (GA) and abscisic acid (ABA) and reduced the amount of jasmonic acid (JA) in susceptible Dorella at 3 and 4 weeks after seed germination. Enhanced levels of phytoalexins, mainly sakuranetin, were detected in $F$. fujikuroi-inoculated resistant cultivar Selenio.

While Ji et al. (2016) and Matić et al. (2016) have revealed abundant genes differentially expressed in the leaves of $F$. fujikuroi-inoculated plants, their sampling strategies may have led to the discovery of genes involved in systemic rather than localized defensive responses. According to our previous evaluation of $F$. fujikuroi colonization on eight rice cultivars at $21 \mathrm{dpi}$, the average re-isolation frequencies of $F$. fujikuroi were $96 \%, 67 \%, 40 \%, 32 \%$, and $25 \%$ from the stem segments $0-1 \mathrm{~cm}, 1-2 \mathrm{~cm}, 2-3 \mathrm{~cm}, 3-4 \mathrm{~cm}$, and $4-5 \mathrm{~cm}$ above the base of the infected seedlings, respectively (Chen et al. 2015). This suggested a localized but not systemic infection of $F$. fujikuroi at early stage of disease development.

In this study, to understand the early lines of defense against $F$. fujikuroi in a susceptible cultivar, Zerawchanica karatals (ZK), and a resistant cultivar, Tainung 67 (TNG67), we first clarified the initial extent of F. fujikuroi colonization in different rice tissues by performing realtime quantitative PCR (qPCR) assays. We found that the stem serves as an initial colonization site so the stem tissues at $7 \mathrm{dpi}$ were selected as a target for transcriptome analysis. A set of genes up- and down-regulated in response to $F$. fujikuroi infection, including genes involved in signal perception and transduction plant defense pathways, were identified and validated by real-time 
quantitative reverse transcription PCR (qRT-PCR) of individual plant samples from additional independent trials. To verify the involvement of JA signaling in rice resistance against bakanae disease, the effects of exogenous JA on rice and F. fujikuroi were also examined.

\section{Materials and Methods Plant Materials}

A susceptible rice cultivar, $\mathrm{ZK}$, and a resistant rice cultivar, TNG67, were used in this study. These cultivars were selected based on resistance screening of 231 diverse rice accessions from Rice Diversity Panel 1 (RDP1) (Chen et al. 2019). ZK was moderately susceptible and TNG67 was moderately resistant (Additional file 8: Fig. S1). In repeated experiments, the two cultivars grew well and showed consistent symptoms after $F$. fujikuroi inoculation under growth chamber conditions. Rice seeds were provided by the Genetics Stocks Oryza (GSOR) germplasm collection (Agricultural Research Service, US Department of Agriculture) and multiplied in the field at the Crop Science Division, Taiwan Agricultural Research Institute.

\section{Inoculation of $F$. fujikuroi}

F. fujikuroi isolate $\mathrm{Ff} 266$ was cultured on $1 / 2$ potato dextrose agar (PDA) for 4 days at $25^{\circ} \mathrm{C}$ under a 12 -h photoperiod. The conidia were collected using sterile $\mathrm{dH}_{2} \mathrm{O}$ and a sterile tip, then adjusted to $1 \times 10^{5}$ spores $/ \mathrm{ml}$. Rice seeds were surface sterilized in $60^{\circ} \mathrm{C}$ sterile $\mathrm{dH}_{2} \mathrm{O}$ for 10 min then immersed in sterile $\mathrm{dH}_{2} \mathrm{O}$ for 2 days at room temperature. The pre-germinated seeds were soaked in the spore suspension (inoculated) or sterile $\mathrm{dH}_{2} \mathrm{O}$ (mock) overnight, then sown in pots ( $\mathrm{L} \mathrm{x} \mathrm{Wx}$ $\mathrm{H}=3.5 \times 4.5 \times 5.5 \mathrm{~cm}$ ) filled with Akadama soil (a granular volcanic clay-like mineral naturally occurring in Japan). Plants were cultivated in the dark for the first 2 days and subsequently under a 12 -h photoperiod in a walk-in chamber set at a $32{ }^{\circ} \mathrm{C}$ day $/ 28^{\circ} \mathrm{C}$ night temperature. Disease severity index (DSI) was calculated based on visual ratings of individual plants at $21 \mathrm{dpi}$ using a 0-3 scale (Chen et al. 2016; Chen et al. 2019) as follows: DSI $=\frac{\sum \text { Rating scale } \times \text { No.of seedlings at the scale }}{\text { Max.scale } \times \text { Total No.of seedlings }} \times 100 \%$.

\section{DNA Extraction and Quantification of $F$. fujikuroi in Different Rice Tissues}

qPCR was conducted to determine the sites colonized by F. fujikuroi in rice. Inoculation of ZK and TNG67 with F. fujikuroi Ff266 was conducted as described above in two independent trials, with 6-8 plants per cultivar in each trial. The aerial and root samples were collected at $3 \mathrm{dpi}$, and the leaf, stem, and root samples were collected at $7 \mathrm{dpi}$. In this study, the stem was defined as the aerial part between the base and the second node of a seedling (Fig. 2 in the study of Chung et al. 2016). DNA extraction and GPCR analysis were conducted on an individual plant basis. Genomic DNA was extracted from different tissues of the inoculated and non-inoculated healthy rice plants, and from 4-day-old F. fujikuroi colonies cultured on 1/2 PDA using a standard cetyltrimethylammonium bromide (CTAB) extraction method (Doyle and Doyle 1987). DNA concentration was measured with a NanoDrop ${ }^{\circ}$ ND-1000 spectrophotometer (Thermo Scientific, Wilmington, DE, USA). qPCR was performed in three technical replicates with the ABI Prism 7500 sequence detection system (Applied Biosystems, Carlsbad, CA, USA). Each qPCR reaction contained $5 \mu$ l SYBR Premix EX Taq II (Ti RNase H Plus) (Takara Bio, Shiga, Japan), $0.5 \mu \mathrm{l}$ of $10 \mu \mathrm{M}$ forward primer, $0.5 \mu \mathrm{l}$ of $10 \mu \mathrm{M}$ reverse primer, $1 \mu \mathrm{l}$ (100 ng) DNA, and $3 \mu \mathrm{lddH} \mathrm{H}_{2} \mathrm{O}$. The primers TqF2 (5'-GGCGCGTTTT GCCCTTTCCT-3') and TqR (5'-AGCGGCTTCCTA TTGTCGAA-3') (Carneiro et al. 2017) specifically targeting the translation elongation factor 1- $\alpha$ gene in $F$. fujikuroi were used. Standard curves were generated for different rice tissues by mixing a serial dilution of $F$. fujikuroi DNA (10 ng, $2 \mathrm{ng}, 400 \mathrm{pg}, 80 \mathrm{pg}$, and $16 \mathrm{pg}$ ) and healthy rice DNA (90 ng, $98 \mathrm{ng}, 100 \mathrm{ng}, 100 \mathrm{ng}$, and 100 ng of DNA from different tissues of ZK and TNG67).

\section{RNA Extraction and cDNA Preparation}

Total RNA was extracted using TRIzol $^{\circ}$ Reagent (Invitrogen $^{\text {tw }}$ Life Technology, Carlsbad, CA, USA) following the manufacturer's instructions. The TURBO DNA-free ${ }^{\mathrm{m}}$ Kit (Invitrogen ${ }^{\text {ma }}$ Life Technology, Carlsbad, CA, USA) was used to remove potentially contaminating DNA. RNA concentration was measured using a NanoDrop ${ }^{\circ}$ ND-1000 spectrophotometer (Thermo Scientific, Wilmington, DE, USA). cDNA was synthesized using the PrimeScript $^{\text {ta }}$ RT Reagent Kit (Takara Bio, Shiga, Japan) following the manufacturer's instructions.

\section{Transcriptome Analysis}

Total RNA samples were extracted from the stem tissues of $F$. fujikuroi-inoculated and $\mathrm{dH}_{2} \mathrm{O}$-treated $\mathrm{ZK}$ and TNG67 seedlings collected at $7 \mathrm{dpi}$ from two independent inoculation trials (carried out in August and December, 2015). The stem tissues were cut with scissors and snap-frozen in liquid nitrogen. Each RNA sample was extracted from stem tissues pooled from 40 individual plants per cultivar per treatment per trial. In each trial, to ensure that the inoculation was successful, we kept another set of plants for continuous observation of symptom development until 21 dpi. Eight RNA samples [two cultivars, two treatments (inoculated and mock), and two biological replicates (each containing 40 plants from an independent inoculation trail)] were used for strand-specific RNA sequencing (insert size 150-180 bp; 
$2 \times 150 \mathrm{bp}$ paired-end reads) on the Illumina $\mathrm{HiSeq}^{\circ}$ 2500 Sequencing System at Sequencing Technology Company Limited (Taipei, Taiwan). The quality of RNA and the libraries were inspected using an Agilent 2100 bioanalyzer (Agilent Technologies, Palo Alto, CA, USA).

Transcriptome data were analyzed using the ContigViews web server (www.contigviews.bioagri.ntu.edu.tw) (Liu et al. 2014). Bowtie 2 (Langmead and Salzberg 2012) was used for calculation of gene expression and reference based mapping (default parameters). Rice OsNipponbare-Reference-IRGSP-1.0 [from Ensembl Genomes (Kersey et al. 2017)] was used as a reference for read mapping and gene annotation. RNA-seq data were deposited in the NCBI Sequence Read Archive database under the accession numbers SAMN13972374 to SAMN13972381.

Principal component analysis (PCA) was conducted to determine the relatedness of different samples. The PCA plot was generated using the DESeq package version 1.36.0 in R with the plotPCA function (Anders and Huber 2010). For each cultivar, differential gene expression between $F$. fujikuroi-inoculated and control seedlings was analyzed using the DESeq package version 1.36 .0 in $\mathrm{R}$ with the "pooled-CR" method and a "maximum" sharing mode (Anders and Huber 2010). Genes with $p$ value $\leqq 0.05, \log _{2}$ fold change $\left(\log _{2} \mathrm{FC}\right) \geqq|1|$, and Fragments Per Kilobase of transcript per Million mapped reads (FPKM) $\geqq 1$ were recognized as significantly differentially expressed genes (DEGs). DEGs were subject to GO term enrichment analysis [false discovery rate (FDR) (Hochberg) $\leqq 0.1$ ] using AgriGO v.2 (Du et al. 2010; Tian et al. 2017). Mapman 3.6.0 (Thimm et al. 2004) was used to analyze the DEGs in the biotic stress and pattern-recognition receptor (PRR) categories. DEGs were also input into Reactome (Croft et al. 2013; Fabregat et al. 2017) for molecular pathway analysis. Plant Transcription Factor Database v4.0 (PlantTFDB) (Jin et al. 2017; Jin et al. 2015; Jin et al. 2013) was used for prediction and classification of transcription factors (TFs).

\section{qRT-PCR Analysis}

To validate the expression of candidate genes, an additional two independent inoculation trials were conducted. The stem tissues were collected at $3 \mathrm{dpi}$ and $7 \mathrm{dpi}$ from six to eight individual plants per cultivar per treatment per trial. RNA extraction and cDNA synthesis were conducted as described above. Relative gene expression was measured (on an individual plant basis) in three technical replicates with the ABI Prism 7500 sequence detection system (Applied Biosystems, Carlsbad, CA, USA). Each qRT-PCR reaction contained $5 \mu$ SYBR Premix EX Taq II (Ti RNase H Plus) (Takara Bio, Shiga, Japan), $0.5 \mu \mathrm{l}$ of $10 \mu \mathrm{M}$ forward primer, $0.5 \mu \mathrm{l}$ of $10 \mu \mathrm{M}$ reverse primer, $1 \mu \mathrm{l} \mathrm{cDNA}$, and $3 \mu \mathrm{l}$ $\mathrm{ddH}_{2} \mathrm{O}$. Primer sequences for qRT-PCR are listed in
Additional file 1: Table S1 (Jain et al. 2017; Li et al. 2016; Sathe et al. 2019; Manosalva et al. 2009; Zhang et al. 2009). Primers were designed using Primer 3 Plus (Version 2.4.1) (Untergasser et al. 2012). To avoid nonspecific binding, candidate primers were further analyzed using prfectBLAST (Santiago-Sotelo and Ramirez-Prado 2012) to perform searches against the rice genome. qRT-PCR was performed using the following thermal cycling parameters: $95^{\circ} \mathrm{C}$ for $30 \mathrm{~s}$ followed by 40 cycles of $5 \mathrm{~s}$ at $95^{\circ} \mathrm{C}$ and $34 \mathrm{~s}$ at $60^{\circ} \mathrm{C}$. The rice gene Elongation factor 1-alpha (OsEF1 $\left.\alpha\right)$ was used as an internal control for normalization of the cycle threshold $(\mathrm{Ct})$ values in different samples (Manosalva et al. 2009). The relative gene expression levels were calculated by the comparative $\mathrm{Ct}\left(2^{-\triangle \Delta \mathrm{Ct}}\right)$ method (Livak and Schmittgen 2001).

\section{MeJA Treatment}

Rice seeds were soaked in $0.1 \mathrm{mM}$ or $0.01 \mathrm{mM}$ methyl jasmonate (MeJA) (Sigma-Aldrich, St. Louis, MO, USA) or $\mathrm{dd}_{2} \mathrm{O}$ (control) for $8 \mathrm{~h}$ at $25^{\circ} \mathrm{C}$ before or after $F$. fujikuroi inoculation. The MeJA solutions and $\mathrm{dd}_{2} \mathrm{O}$ were adjusted to $\mathrm{pH}=5$. The concentrations of MeJA were chosen according to previous studies on the effects of exogenous JA on disease resistance in rice (Ji et al. 2015; Chen et al. 2018). The inoculation of $F$. fujikuroi and rating of disease severity at $14 \mathrm{dpi}$ and $21 \mathrm{dpi}$ were conducted as described above. The experiment was performed in two independent trials, each with 12-15 individual plants per treatment per cultivar.

The effects of MeJA on F. fujikuroi were also assessed. For the spore germination test, $10 \mu \mathrm{l}$ of $F$. fujikuroi spore suspension $\left(5 \times 10^{4}\right.$ spores $/ \mathrm{ml}$ in $1 / 2$ potato dextrose broth) mixed with an equal volume of MeJA (final concentration: $0.1 \mathrm{mM}$ or $0.01 \mathrm{mM}$ ) or $\mathrm{ddH}_{2} \mathrm{O}$ (pH adjusted to 5) was placed on a glass slide. After incubation in a moist chamber for $12 \mathrm{~h}$ at $25^{\circ} \mathrm{C}, 100$ spores on each glass slide were inspected for germination under the microscope. A spore with a protruding germ tube two times longer than its largest diameter was considered germinated (Chen et al. 2016). The experiment was performed in two independent trials, each with three glass slides per treatment. For the colony growth test, $100 \mu \mathrm{l}$ of $F$. fujikuroi spores $\left(1 \times 10^{5}\right.$ spores $/ \mathrm{ml}$ in $\mathrm{ddH}_{2} \mathrm{O}$ ) was mixed with an equal volume of MeJA (final concentration: $0.1 \mathrm{mM}$ or $0.01 \mathrm{mM}$ ) or $\mathrm{dd}_{2} \mathrm{O}$ (pH adjusted to 5). After incubation for $8 \mathrm{~h}$ at $25^{\circ} \mathrm{C}, 10 \mu \mathrm{l}$ of the spore suspension was transferred to a $1 / 2 \mathrm{PDA}$ plate. Colony diameters were measured after 7 and 10 days of incubation at $25^{\circ} \mathrm{C}$ under a 12 -h photoperiod. The experiment was performed in two independent trials, each with three to five plates per treatment.

\section{Statistical Analysis}

A two-tailed unpaired Student's $t$-test was conducted to analyze the differences between the DSIs of ZK and 
TNG67 at $p<0.05$. Differences among multiple treatments were analyzed by one-way analysis of variance (ANOVA) with Tukey's multiple comparison test at $p<$ 0.05 . Statistical analyses and graphing were performed using GraphPad Prism version 7.04 (GraphPad Software, La Jolla California USA).

\section{Results}

Disease Symptoms of $F$. fujikuroi-Inoculated ZK and TNG67

The symptoms of ZK and TNG67 inoculated with $F$. fujikuroi Ff266 are shown in Fig. 1 and Additional file 9: Fig. S2. ZK started to exhibit mild symptoms at 7-10 dpi and showed typical bakanae disease symptoms such as abnormal stem elongation, a slender stem, and a large leaf angle after $14 \mathrm{dpi}$. On the contrary, TNG67 showed no or only one type of bakanae symptoms at 7,14 , and $21 \mathrm{dpi}$. The DSIs at $21 \mathrm{dpi}$ were $56.2 \pm 3.4 \%$ (mean $\pm \mathrm{SE}$ ) for ZK and $11.0 \pm 1.9 \%$ for TNG67 $(p<0.0001)$. To clarify the early responses of the two cultivars before full development of disease symptoms, we chose $7 \mathrm{dpi}$ as the time point for subsequent transcriptome analysis.

\section{Quantification of $F$. fujikuroi in Different Rice Tissues}

Focusing on the early stages of disease development, qPCR was conducted to determine the levels of $F$. fujikuroi colonization in different parts of rice seedlings at 3 and $7 \mathrm{dpi}$. In our qPCR assays, the coefficient of determination $\left(R^{2}\right)$ values for the standard curves based on different rice tissues were all $>0.99$ (Additional file 10:

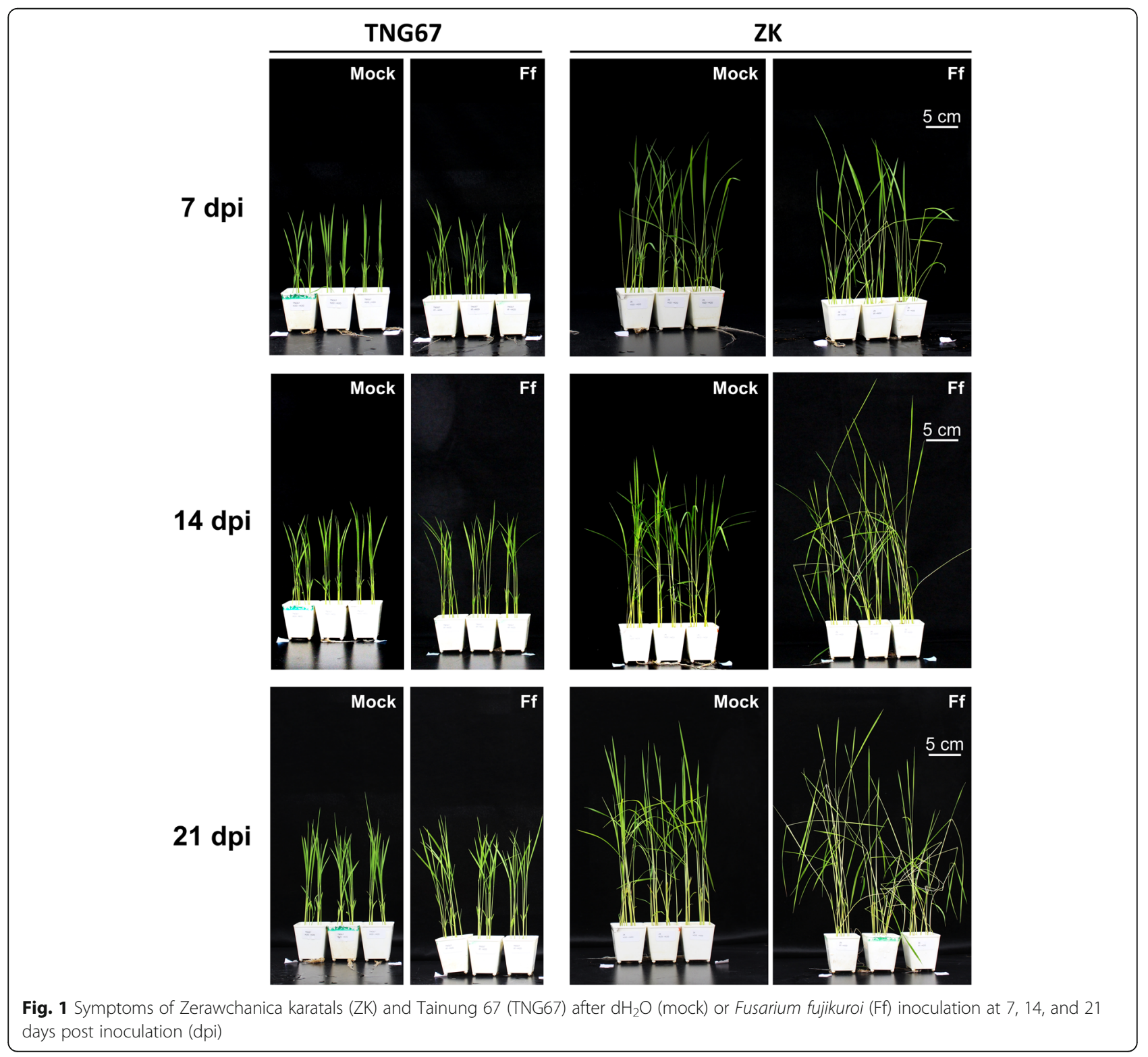


Fig. S3). Similar amounts of F. fujikuroi were detected in the roots and aerial parts of both cultivars at 3 dpi. For both cultivars at $7 \mathrm{dpi}, F$. fujikuroi colonization was detected in the root and stem but not in the leaf tissues (Fig. 2). No significant differences were detected between the root and stem tissues or between the two cultivars.

\section{Transcriptome Profiling and Identification of Differentially} Expressed Genes

RNA sequencing was conducted to reveal gene expression patterns in the stem tissues of ZK and TNG67 at 7 dpi. The number of reads and mapping rates for the eight RNA libraries are shown in Additional file 2: Table S2. An average of $7.5 \mathrm{~Gb}$ raw reads (40-62 million sequences, $150 \mathrm{bp}$ in length) was generated for each sample, and $79.13 \%-82.95 \%$ of clean reads were mapped to the reference exon regions. The total numbers of transcripts identified were 35,683 in ZK and 35,926 in TNG67. The expression levels of all transcripts are provided in Additional file 3: Table S3. PCA was conducted to assess transcriptional variation among cultivars, treatments, and trials (Additional file 11: Fig. S4a). A distinct separation between ZK and TNG67 was observed along PC1. PC2 showed that the same trial-cultivar combination clustered more closely together, suggesting that the variability between treatments were smaller than between different trials.

By comparing F. fujikuroi-inoculated libraries with the mock libraries, 169 and 118 DEGs were identified in ZK and TNG67 (Additional file 11: Fig. S4b and Additional file 4: Table S4), respectively. The expression profiles of the DEGs in ZK and TNG67 are shown in Additional file 11: Fig. S4c. There were 40 up-regulated DEGs in ZK and 87 in TNG67, and 129 down-regulated DEGs in ZK and 31 in TNG67. ZK and TNG67 only shared two DEGs: OsWRKY71 (Os02g0181300; downregulated in both cultivars) and $O s D B H$ (DEAD-Box Helicase, Os04g0486800; down-regulated in ZK and upregulated in TNG67).

\section{GO Enrichment Analysis}

DEGs were classified into three major GO categories: biological process, molecular function, and cellular component. For ZK and TNG67, 63 and 22 enriched GO terms were identified, respectively (Fig. 3). TNG67 showed no enriched GO terms in the cellular component category. Moreover, most of the GO terms enriched in TNG67 DEGs [all terms except for "transmembrane transport" (GO:0055085), "transport" (GO: 0006810), "establishment of localization" (GO:0051234),

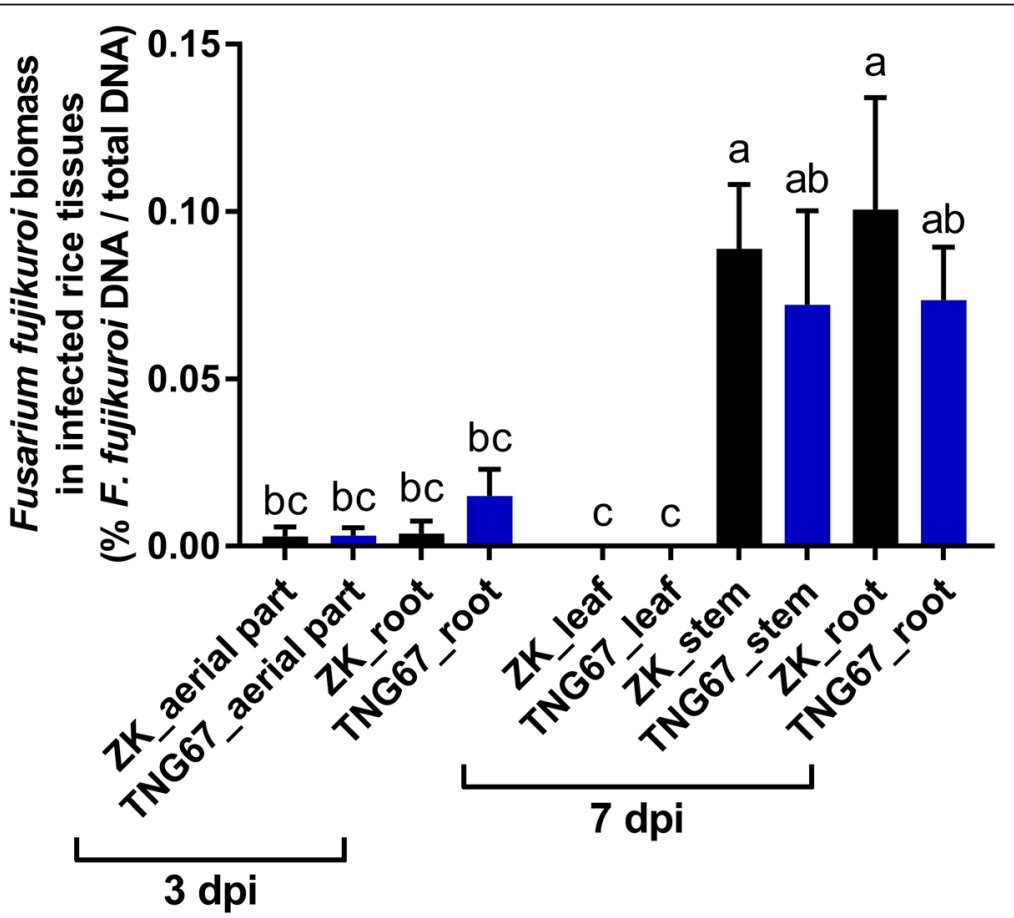

Fig. 2 Quantification of Fusarium fujikuroi in different tissues of Zerawchanica karatals (ZK) and Tainung 67 (TNG67) at 3 and 7 days post inoculation (dpi). Data are mean \pm SEM ( $n=2$ independent trials with six to eight plants per treatment per trial). Different letters indicate significant difference based on Tukey's multiple comparison test at $p<0.05$ 


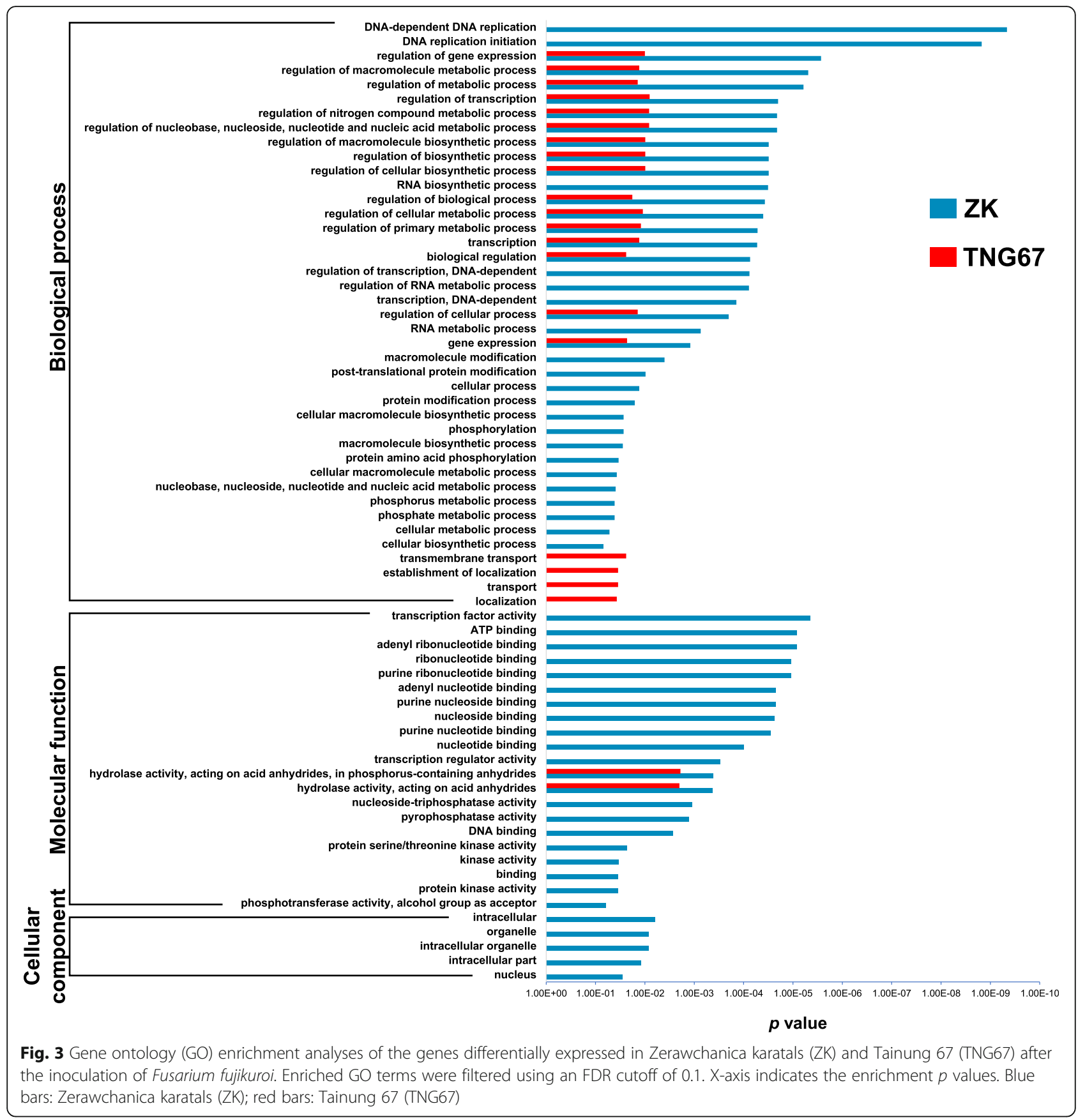

and "localization" (GO:0051179)] were also enriched in ZK DEGs. Some GO terms were specific to ZK, including "transcription factor activity" (GO:0003700), "posttranslational protein modification" (GO:0043687), and four GO terms associated with phosphorylation [i.e., "phosphorus metabolic process" (GO:0006793), "phosphate metabolic process" (GO:0006796), "phosphorylation" (GO:0016310), and "protein amino acid phosphorylation" (GO:0006468)]. GO terms associated with plant responses to biotic stresses were not enriched in TNG67 or ZK DEGs.

\section{DEGs Related to Biotic Stress and Pattern Recognition Receptors}

Mapman analysis identified 57 DEGs (37 in ZK and 21 in TNG67, with 1 DEG in both cultivars) in the biotic stress category (Additional file 4: Table S4). These included 9 PRRs and 17 TFs. While a large proportion of biotic stress-related genes were down-regulated in susceptible $\mathrm{ZK}$, more up-regulated genes were found in resistant TNG67 (ZK: 31 down- and 6 up-regulated biotic stress DEGs; TNG67: 12 up- and 9 down-regulated biotic stress DEGs). 
Plants deploy membrane-associated receptor-like kinases and receptor-like proteins as PRRs to detect a wide range of pathogen- or damage-associated molecular patterns (PAMPs or DAMPs). PAMP-PRR pairs function as multi-protein complexes to activate defense signaling pathways and responses, known as pattern-triggered immunity (Monaghan and Zipfel 2012; Zipfel 2014). This study identified 10 differentially expressed PRRs, six in ZK [Os03g0297800, Os04g0576900 (XIAO), Os05g0207700, Os07g0628700, Os08g0117700, Os08g0501700 (OsWAK76)] and four in TNG67 [Os06g0134700, Os07g0550900, Os09g0110100, Os12g0145900] (Additional file 4: Table S4). Notably, in ZK, all except OsWAK76 were down-regulated; but in TNG67, all except Os07g0550900 were up-regulated.

\section{DEGs Annotated as TFs}

TFs regulate the transcription of target genes by binding to specific DNA regions (Latchman 1997). TFs and their transcriptional regulatory networks play crucial roles in plant development and stress responses. Twenty-three out of 169 (13.6\%) DEGs in ZK and 14 out of 118 (11.9\%) DEGs in TNG67 were annotated as TFs (Additional file 4: Table S4). These included five WRKYs and seven ethylene response factors (ERFs). WRKY proteins bind to W-box elements in the promoter regions of many defense-related genes (Chen and Ronald 2011; Dong et al. 2003). The five differentially expressed WRKYs [OsWRKY21 (Os01g0821600) and OsWRKY24 (Os01g0826400) in ZK; OsWRKY1 (Os01g0246700) and OsWRKY28 (Os06g0649000) in TNG67, and OsWRKY71 (Os02g0181300) in both ZK and TNG67] were all down-regulated. ERFs have been reported to be involved in biotic and abiotic responses, hormone signaling transduction, and development (Nakano et al. 2006). ERFs bind to promoter regions containing AGCCGCC motifs (GCC box) to trigger stress-responsive gene expression (Müller and Munné-Bosch 2015; Ku et al. 2018). Seven down-regulated ERFs [OsERF53 (Os01g0224100), OsERF54 (Os01g0657400), OsERF25 (Os02g0677300), OsERF30 (Os04g0572400), OsERF26 (Os06g0127100), OsERF104 (Os08g0474000), OsERF133 (Os09g0522100)] were identified in ZK. None of the ERFs in resistant TNG67 were identified as DEGs.

\section{DEGs Involved in the JA Signaling Pathway}

The expression of genes involved in JA, ethylene, salicylic acid (SA), and GA biosynthesis and signaling pathways are shown in Additional file 5: Table S5. Differential expression was not observed for all genes participating in biosynthesis pathways. Among the genes involved in various phytohormone signaling pathways, only four associated with JA signaling were identified as DEGs in ZK: three down-regulated jasmonate ZIMdomain (JAZ) genes [OsJAZ9 (Os03g0180800), OsJAZ10
(Os03g0181100), and OsJAZ13 (Os10g0391400)] and an up-regulated histone deacetylase $(H D A)$ gene, $H D A 703$ (Os02g0214900; $\log _{2} \mathrm{FC}=3.02$ ). JAZ proteins can directly bind to the basic helix-loop-helix TFs MYCs, resulting in inhibition of the expression of JA-responsive genes (Cheng et al. 2011; Fernández-Calvo et al. 2011). HDAs can be recruited by the transcription co-repressor TOPLESS, which leads to chromatin remodeling and suppression of JA-responsive gene expression (Long et al. 2006; Wu et al. 2008).

\section{qRT-PCR Analysis}

qRT-PCR was conducted to quantify the expression levels of 11 genes at $7 \mathrm{dpi}$ and 5 genes at $3 \mathrm{dpi}$ and $7 \mathrm{dpi}$ (Fig. 4 and Fig. 5 show the results from one of two independent trials in which similar trends were observed; $\log _{2} \mathrm{FC}$ values from two trials are in Additional file 6: Table S6). These genes were chosen because of their potential functions in disease resistance and their significant induction or repression in response to F. fujikuroi. They included four PRRs (Os03g0297800, XIAO, Os08g0117700, Os09g0110100), four WRKYs (OsWRKY21, OsWRKY24, OsWRKY28, and OsWRKY71), three ERFs (OsERF53, OsERF54, and OsERF133), three JAZs (OsJAZ9, OsJAZ10, and OsJAZ13), and two SA marker genes [phenylalanine ammonia-lyase (OsPAL1, Os02g0626100) and non-expressor of pathogenesis-related (OsNPR1, Os01g0194300)]. All of the selected genes except for the two SA marker genes are DEGs identified from the transcriptome analysis. All 14 selected DEGs were confirmed to be significantly up- or down-regulated in F. fujikuroi-inoculated ZK and/or TNG67 (Fig. 4 and Additional file 6: Table S6). The qRT-PCR results were generally consistent with the transcriptome data. The only exceptions were OsWRKY71 and OsERF53 in ZK (they were found to be downregulated at $7 \mathrm{dpi}$ in $\mathrm{ZK}$ according to the transcriptome analysis; however, no significant difference was detected by qRT-PCR; on the other hand, the down-regulation of OsWRKY71 and up-regulation of OsERF53 in TNG67 were confirmed by qRT-PCR).

Five genes functioning in JA- and SA-related pathways were tested for their expression at $7 \mathrm{dpi}$ and an earlier stage (3 dpi) (Fig. 5 and Additional file 6: Table S6). The JA signaling pathway genes OsJAZ9, OsJAZ10, and OsJAZ13 were significantly down-regulated at $7 \mathrm{dpi}$ in ZK and TNG67 $\left(\log _{2} \mathrm{FC}=-1.44\right.$ to -5.69$)$. Downregulation was also observed at $3 \mathrm{dpi}$, but to a smaller extent $\left(\log _{2} \mathrm{FC}=-0.53\right.$ to -3.59$)$. At $3 \mathrm{dpi}$, significant down-regulation of OsJAZ9 in TNG67 and OsJAZ10 and OsJAZ13 in ZK was observed; a slight decrease (not significant) was observed for OsJAZ9 in ZK and OsJAZ10 and OsJAZ13 in TNG67. For OsPAL1, which encodes a key enzyme that catalyzes the biosynthesis of SA and phenolic compounds (Lee et al. 1995; D'Maris Amick Dempsey et al. 2011), no differential expression was 


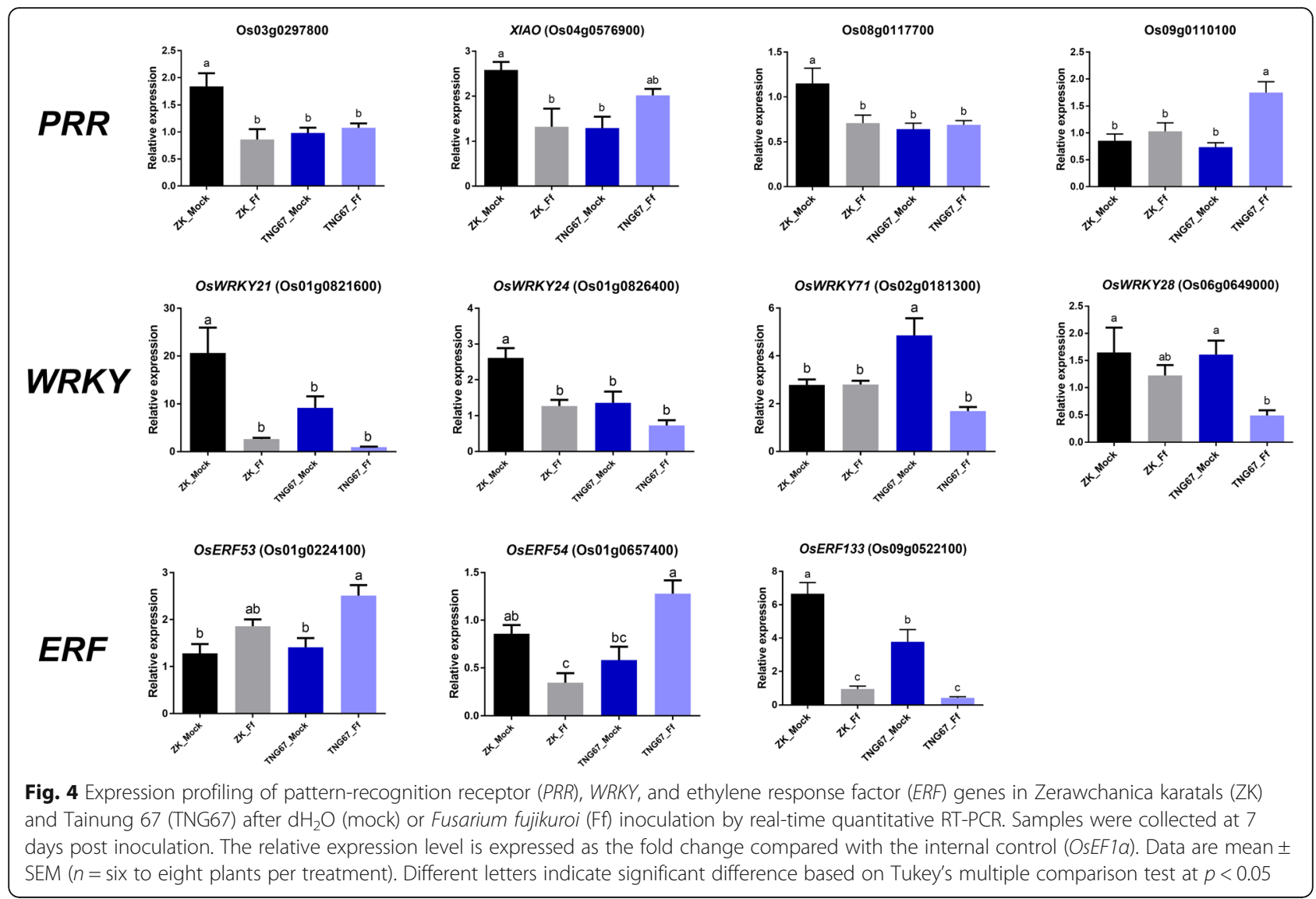

found between the inoculated and mock samples at 3 and 7 dpi in both cultivars. For OsNPR1, which encodes a positive regulator controlling SA-mediated defense responses and systemic acquired resistance (Yuan et al. 2007; Dong 2004), we detected no significant difference at $3 \mathrm{dpi}$ in both cultivars, but significant up-regulation at 7 dpi in $\mathrm{ZK}\left(\log _{2} \mathrm{FC}=0.93\right)$.

\section{MeJA-Induced Resistance to $F$. fujikuroi}

To understand whether JA mediates resistance to F. fujikuroi in rice, the effects of MeJA treatment (before or after F. fujikuroi inoculation) on disease severity at 14 dpi and 21 dpi were investigated (Fig. 6). For susceptible $\mathrm{ZK}$, as compared with $\mathrm{ddH}_{2} \mathrm{O}$ treatment, MeJA treatment of rice seeds significantly alleviated and delayed the development of bakanae symptoms. No significant difference was observed between the $0.01 \mathrm{mM}$ and 0.1 mM MeJA treatments; however, MeJA treatment before F. fujikuroi inoculation more effectively enhanced resistance than MeJA treatment after the inoculation. When treated with MeJA before inoculation, ZK plants showed $\mathrm{a} \sim 0.5$ - and $\sim 0.8$-fold reduction in DSI compared with the control at 14 and $21 \mathrm{dpi}$, respectively. MeJA treatment after inoculation caused a $\sim 0.7$-fold reduction and no significant reduction compared with the control at 14 and $21 \mathrm{dpi}$, respectively. Under all treatments, TNG67 exhibited similar levels of high resistance at 14 and 21 dpi (average DSI $=0 \%-11.1 \%$ ).

\section{Effect of MeJA on the Viability of $F$. fujikuroi}

To ensure that the observed JA-induced bakanae resistance was not due to the inhibitory effect of JA on the pathogen, F. fujikuroi spores were treated with MeJA or $\mathrm{dd}_{2} \mathrm{O}$ then evaluated for germination rate and colony growth. More than $99.5 \%$ of the spores germinated within $12 \mathrm{~h}$, and the colony diameters were $\sim 4 \mathrm{~cm}$ after 7 days and $\sim 5.8 \mathrm{~cm}$ after 10 days of growth on 1/2 PDA (Additional file 7: Table S7). No significant differences were observed between the $\mathrm{ddH}_{2} \mathrm{O}, 0.01 \mathrm{mM}$ MeJA, and $0.1 \mathrm{mM}$ MeJA treatments.

\section{Discussion}

While rice defenses against leaf pathogens such as Magnaporthe oryzae and Xanthomonas oryzae pv. oryzae have been extensively explored and elucidated (Azizi et al. 2016; Nasir et al. 2018; Liu et al. 2013; Ji et al. 2018b; White and Yang 2009), the modulation of immunity responses during interaction with the seed-borne pathogen $F$. fujikuroi remains largely unknown. Profiling of $F$. fujikuroi-induced gene expression in rice has 


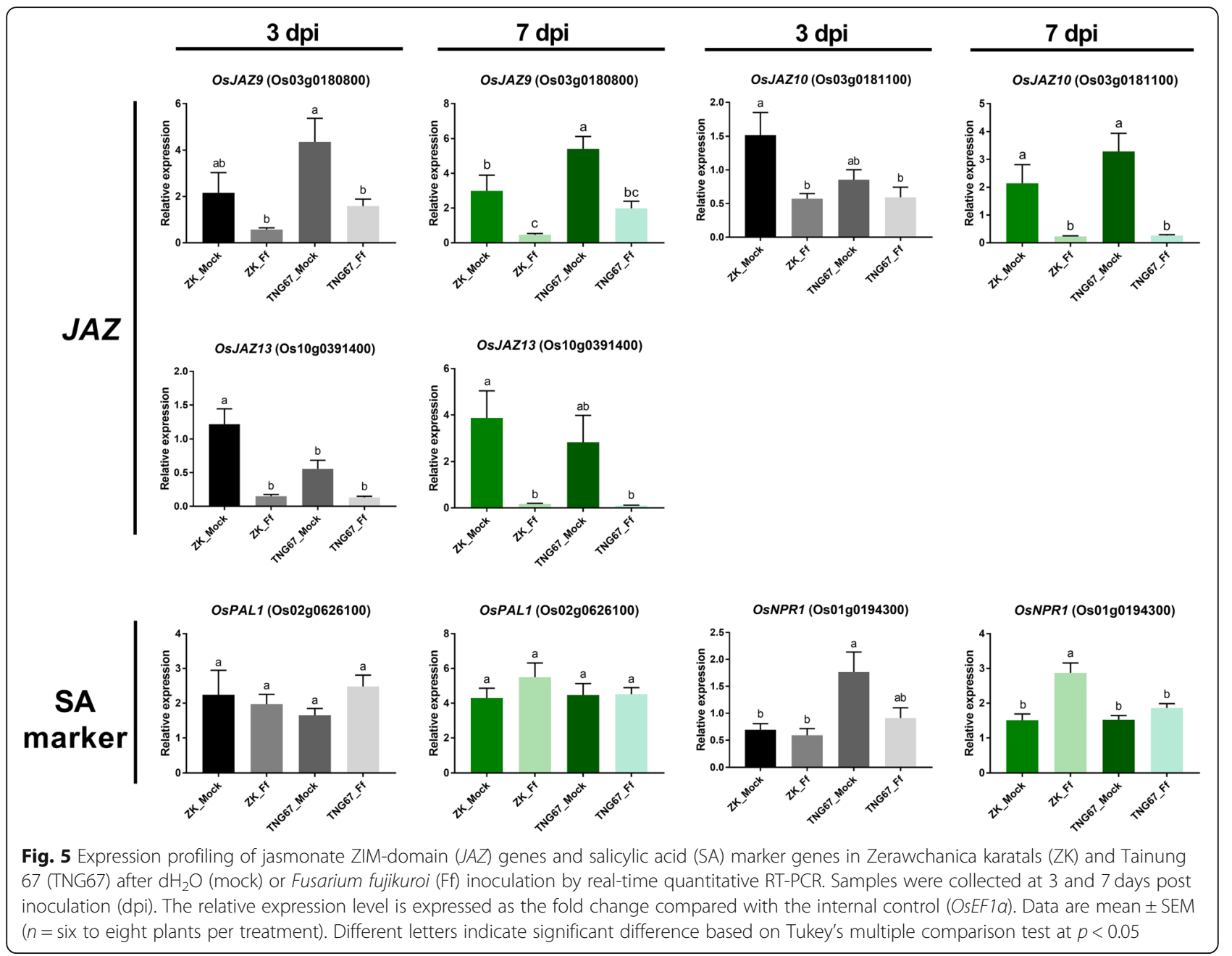

previously involved analyses of rice leaves at 7 and 21 dpi (Ji et al. 2016; Matić et al. 2016). Although F. fujikuroi infection can cause abnormal growth of the whole rice seedling, our qPCR analysis revealed that $F$. fujikuroi colonizes the stem and roots, but not the leaves. Aiming to uncover the defense mechanisms at an early stage of pathogenesis, we sequenced the total RNA of $F$. fujikuroi-colonized rice stem tissues at $7 \mathrm{dpi}$ at a higher coverage and with longer reads [in comparison with 87.2 million reads of $50 \mathrm{bp}$ per read generated by Ji et al. 2016 and 17 million reads of $51 \mathrm{bp}$ per read generated by Matić et al. 2016, we generated 40-62 million reads of $150 \mathrm{bp}$ per read for each sample]. Our qRT-PCR analysis of 14 DEGs and two SA marker genes, using RNA samples isolated from individual plants from two additional inoculation trials, validated the expression pattern of up- and down-regulated defense-related genes.

In this study, DEGs associated with plant defense were mainly classified in three categories: PRRs, TFs, and JA signaling pathway-related genes. Fewer DEGs were found in resistant TNG67 $(n=118)$ than susceptible ZK $(n=$
169), which is consistent with the finding of Matic et al. (2016): the numbers of DEGs in resistant Selenio and susceptible Dorella were 80 and 1285 at $7 \mathrm{dpi}$, and 3119 and 5095 at $21 \mathrm{dpi}$, respectively (the criteria for calling DEGs were FDR $\leqq 0.05$ and |fold change $\mid \geqq 2$ ). The DEGs and enriched GO terms identified in this study were largely different from those identified in the previous two transcriptome studies (Ji et al. 2016; Matić et al. 2016), perhaps reflecting the difference between systemic resistance in leaves versus local defense in stem tissues. It also suggests complex and variable mechanisms governing resistance or susceptibility to $F$. fujikuroi infection in different cultivars. Notably, Ji et al. (2019) recently analyzed the proteomics of $F$. fujikuroi-infected plants at $7 \mathrm{dpi}$. The protein encoded by a DEG we identified in TNG67, limonene synthase (Os04g0340300; LOC4335518), was found to be up-regulated in both the resistant cultivar 93-11 and the susceptible cultivar Nipponbare by Ji et al. (2019). Limonene has antifungal and antibacterial activities; another limonene synthase gene OsTPS19 in rice was found to be induced upon $M$. oryzae infection, and 

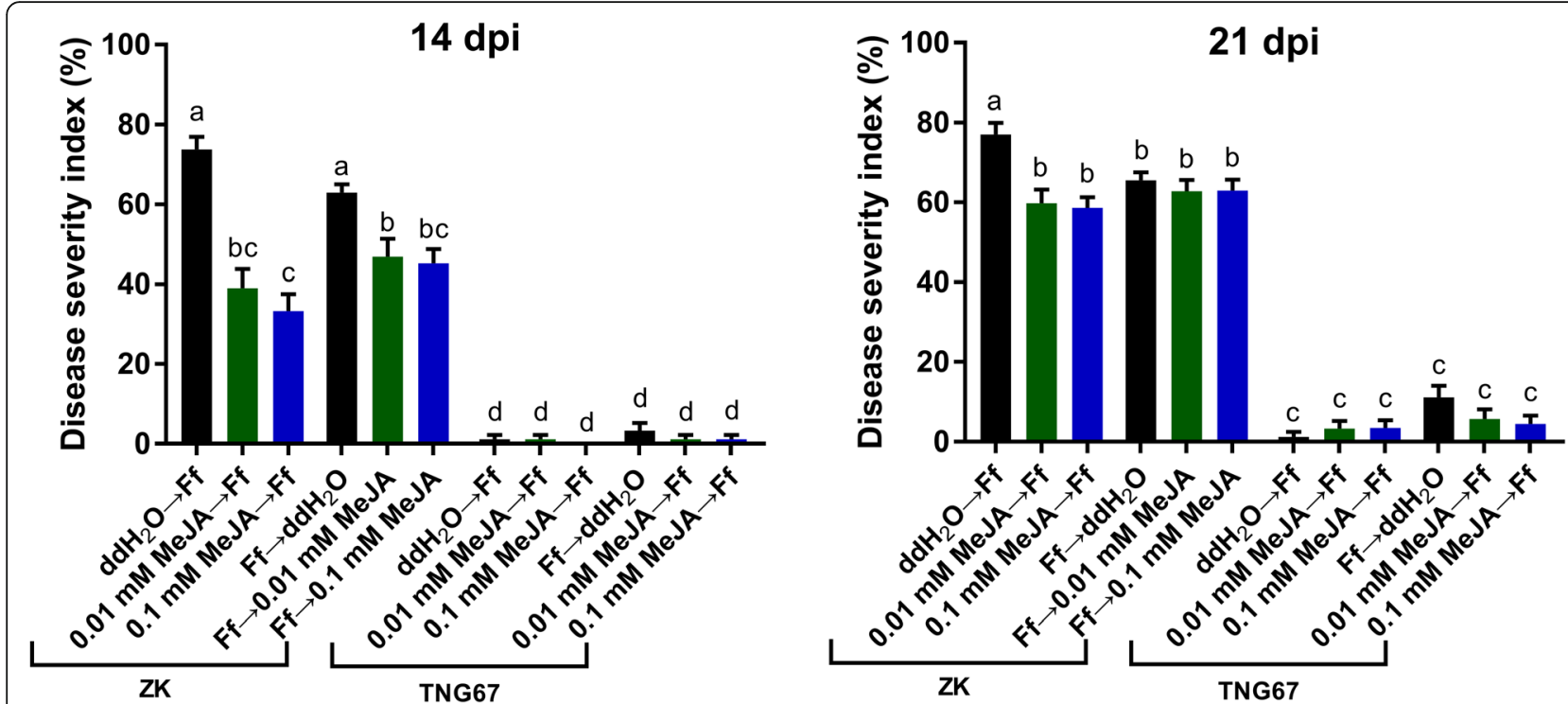

Fig. 6 Effect of methyl jasmonate (MeJA) on disease severity indexes of Zerawchanica karatals (ZK) and Tainung 67 (TNG67) at 14 and 21 days post inoculation (dpi). Rice seeds were treated with $\mathrm{dd}_{2} \mathrm{O}, 0.01 \mathrm{mM}$ MeJA, or $0.1 \mathrm{mM}$ MeJA before or after the inoculation of Fusarium fujikuroi (Ff). Data are mean \pm SEM ( $n=2$ independent trials with 12-15 plants per treatment per trial). Different letters indicate significant difference based on Tukey's multiple comparison test at $p<0.05$

overexpression of OsTPS19 enhanced resistance to M. oryzae (Chen et al. 2018).

In agreement with previous observations, we found that genes involved in phytohormone biosynthesis were not differentially expressed at $7 \mathrm{dpi}$. At 1 and 2 weeks post inoculation (wpi) with $F$. fujikuroi, similar quantities of JA, SA, GA, and ABA accumulated in inoculated and non-inoculated seedlings of both resistant and susceptible cultivars (Siciliano et al. 2015). At 3 wpi but not 1 wpi, genes associated with JA biosynthetic process were up-regulated in resistant Selenio and down-regulated in susceptible Dorella, and genes related to GA metabolic process were up-regulated in susceptible Dorella and down-regulated in resistant Selenio (Matić et al. 2016).

JA has been shown to mediate plant defense against wounding, insect herbivores, and necrotrophic, hemibiotrophic, and biotrophic pathogens (Zhang et al. 2017). Contrasting roles of the JA pathway in response to Fusarium pathogens have been reported. In Arabidopsis, JA signaling has been negatively and positively associated with resistance against Fusarium graminearum (Makandar et al. 2010), and this pathway can be hijacked by Fusarium oxysporum to promote disease development (Thatcher et al. 2009). In the tomato - F. oxysporum f. sp. lycopersici (Thaler et al. 2004), date palm - F. oxysporum f. sp. albedinis (Jaiti et al. 2009), banana - F. oxysporum f. sp. cubense (Sun et al. 2013), and cotton - F. oxysporum f. sp. vasinfectum (Konan et al. 2014) pathosystems, exogenous JA treatment induced host resistance by enhancing production of defense-related phytoalexins (Konan et al. 2014) and enzymes [e.g., polyphenoloxidase and peroxidase (Jaiti et al. 2009)]. In this study, while no differential expression of genes in SA- and GA-related signaling pathways was observed, we detected a significant decrease in OsJAZ9, OsJAZ10, and OsJAZ13 transcripts in both ZK and TNG67 at 3 and 7 days after $F$. fujikuroi inoculation. Because $J A Z$ is a key repressor of JA signaling, the results suggested the activation of JA signaling upon F. fujikuroi infection. We did not observe differential expression of JA- or SA-regulated downstream defense genes (e.g., OsPR1a, OsPR1b, OsWRKY45, OsJAmyb) (Agrawal et al. 2001; Shimono et al. 2007; Agrawal et al. 2000; Lee et al. 2001) in the transcriptome data, perhaps because the stem samples included both $F$. fujikuroi-colonized and noncolonized tissues, and $7 \mathrm{dpi}$ may be too early to detect systemic induction of the whole defense network.

JA signaling appears to play a crucial role in mediating early-stage defense responses against $F$. fujikuroi in rice. Exogenous JA treatment of rice seeds, prior to or after $F$. fujikuroi inoculation, provided enhanced resistance as evidenced by alleviated bakanae symptoms in susceptible ZK. Previous studies showed that exogenous application of MeJA to rice plants induced resistance to the rice blast pathogen M. oryzae (Han and Kahmann 2019), the root knot nematode Meloidogyne graminicola (Nahar et al. 2011; Kyndt et al. 2017), and Rice ragged stunt virus (RRSV) (Zhang et al. 2016). During initial stage of $M$. oryze infection, a fungal secreted monooxygenase may be employed to convert endogenous free JA to $12 \mathrm{OH}-\mathrm{JA}$, thus preventing the induction of rice 
immunity by fungal and host-derived JA (Patkar et al. 2015). RRSV infection in rice was found to induce the production of miR319, which suppressed JA-mediated defense and promoted disease development (Zhang et al. 2016). F. fujikuroi behaves like a necrotroph in susceptible rice genotypes (Ma et al. 2013; Matić et al. 2016), and effectors from necrotrophic pathogens were found to activate the SA pathway while suppressing the JA pathway (Tanaka et al. 2015) [e.g., the exopolysaccharide effector from Botrytis cinerea in tomato (El Oirdi et al. 2011)]. In this study, OsNPR1 was up-regulated in susceptible ZK but not in resistant TNG67 at $7 \mathrm{dpi}$, suggesting the modulation of antagonistic crosstalk between the SA and JA pathways in ZK. GAs produced by $F$. fujikuroi and the host plant could also participate in the regulation of JA signaling through the degradation of DELLA proteins (the repressors of JAZs) (Navarro et al. 2008; De Vleesschauwer et al. 2016). It will be intriguing to elucidate how F. fujikuroi manipulates the phytohormone balance in susceptible rice cultivars to its benefit.

PRRs, WRKYs, and ERFs have been reported to be involved in signal perception and transduction pathways in plant defense and development (Macho and Zipfel 2014; Phukan et al. 2016; Müller and Munné-Bosch 2015). In this study, we identified four PRRs (Os03g0297800, XIAO, Os08g0117700, and Os09g0110100), four WRKYs (OsWRKY21, OsWRKY24, OsWRKY28, and OsWRKY71), and three ERFs (OsERF53, OsERF54, and OsERF133) that exhibited consistent differential expression patterns in both transcriptome and qRT-PCR analyses (contradictory results were only observed for the PRR gene Os08g0117700 in TNG67 and OsERF53 in ZK). Except for OsWRKY28 and OsWRKY71, these selected DEGs were shown for the first time to be associated with disease resistance. Among the four PRRs encoding LRR receptorlike kinases, XIAO was previously found to participate in the regulation of brassinosteroid signaling and cell cycling in rice (Jiang et al. 2012). The xiao mutant displays dwarfism, smaller leaves, flower organs and seeds, and erect leaves (Jiang et al. 2012). At 7 dpi of F. fujikuroi, XIAO was up-regulated in resistant TNG67 and down-regulated in susceptible $\mathrm{ZK}$, indicating a role of brassinosteroids in modulating rice responses to F. fujikuroi.

The four OsWRKY genes we identified were significantly down-regulated in ZK (WRKY21 and WRKY24) or TNG67 (WRKY71 and WRKY28) at $7 \mathrm{dpi}$. In Nipponbare, OsWRKY28 is a negative regulator of basal defense responses against $M$. oryzae (Chujo et al. 2013). OsWRKY71 was annotated as a TF involved in plant defense response (Liu et al. 2007). OsWRKY71 was induced as early as $0.5 \mathrm{~h}$ after treatment with SA, MeJA, or 1-aminocyclo-propane-1-carboxylic acid (ACC; the precursor of ethylene), wounding, or $X$. oryzae pv. oryzae infection, and overexpression of OsWRKY71 activated
OsNPR1 and OsPR1b (Liu et al. 2007). Notably, Ji et al. (2016) showed that OsWRKY71 was up-regulated at 7 dpi in the moderately resistant cultivar 93-11. The opposite expression patterns of OsWRKY71 in 93-11 and TNG67 implies different regulation of OsWRKY71 in the two resistant cultivars. The three ERF genes we identified were significantly up- or down-regulated in ZK or TNG67 at $7 \mathrm{dpi}$, suggesting that they function differently in regulating rice resistance to $F$. fujikuroi. Contrasting roles in disease resistance have been observed for different ERF genes. For example, OsERF922 and OsERF83 were found negatively and positively regulate rice resistance to $M$. oryzae in rice cultivars Zhonghua 17 and Yukihikari, respectively (Liu et al. 2012; Tezuka et al. 2019).

\section{Conclusions}

This study focused on investigating the early lines of defense against F. fujikuroi in rice seedlings. By comparing the transcriptomes of $F$. fujikuroi-infected and healthy stem tissues from plants at $7 \mathrm{dpi}$, we identified 169 DEGs in a susceptible cultivar, ZK, and 118 DEGs in a resistant cultivar, TNG67. qRT-PCR analysis on an individual plant basis enabled precise quantification and validation of 14 DEGs, most of which [12 DEGs, i.e., Os03g0297800, XIAO, Os08g0117700, Os09g0110100, OsWRKY21, OsWRKY24, OsERF53, OsERF54, OsERF133, OSJAZ9, OSJAZ10, and OSJAZ13] had never been associated with disease resistance. Interestingly, among complex phytohormone biosynthesis and signaling pathways, only JA signaling pathway genes were identified as DEGs. Significant repression of OsJAZ9, OsJAZ10, and OsJAZ13 at $3 \mathrm{dpi}$ and $7 \mathrm{dpi}$ in both cultivars, indicated the activation of JA signaling during early interactions between rice and F. fujikuroi. Exogenous MeJA treatment of rice seeds could delay bakanae disease development in susceptible ZK, which also demonstrates the pivotal role of JA in rice resistance against $F$. fujikuroi. Detailed mechanisms underlying JA-mediated bakanae resistance and the novel defense-related DEGs are worthy of further investigation. Moreover, to have comprehensive knowledge on rice defenses in response to $F$. fujikuroi colonization, root transcriptome profiles also deserve to be explored.

\section{Supplementary information}

Supplementary information accompanies this paper at https://doi.org/10. 1186/s12284-020-00426-Z.

Additional file 1: Table S1. Primers used for real-time quantitative reverse transcription PCR (qRT-PCR)

Additional file 2: Table S2. Mapping results for RNA-seq reads from $\mathrm{dH}_{2} \mathrm{O}$-treated or F. fujikuroi-inoculated Zerawchanica karatals (ZK) and Tainung 67 (TNG67) 
Additional file 3: Table S3. Expression levels and functional annotations for all Zerawchanica karatals (ZK) and Tainung 67 (TNG67) transcripts

Additional file 4: Table S4. List of differentially expressed genes (DEGs) in Zerawchanica karatals (ZK) and Tainung 67 (TNG67)

Additional file 5: Table S5. List of genes involved in jasmonic acid, ethylene, salicylic acid and gibberellic acid biosynthesis or signaling pathways

Additional file 6: Table S6. Expression profiling of 14 selected genes by RNA-seq and real-time quantitative RT-PCR (qRT-PCR)

Additional file 7: Table S7. Effects of methyl jasmonate (MeJA) on the germination rate and colony growth of Fusarium fujikuroi

Additional file 8: Fig. S1. Distribution of bakanae disease severity indexes of 231 accessions in rice diversity panel 1. The resistance scores of Zerawchanica karatals (ZK) and Tainung 67 (TNG67) are indicated by arrows. Data from the study of Chen et al. (2019) were adjusted using best linear unbiased estimates (BLUEs) in TASSEL 5.2.24 for control of variation among blocks in different inoculation trials.

Additional file 9: Fig. S2. Symptoms of Zerawchanica karatals (ZK) and Tainung 67 (TNG67) after $\mathrm{dH}_{2} \mathrm{O}$ (mock) or Fusarium fujikuroi (Ff) inoculation at 21 days post inoculation

Additional file 10: Fig. S3. Fusarium fujikuroi genomic DNA standard curves for quantitative real-time PCR ( $(\mathrm{PCCR}$ ). A dilution series of $F$. fujikurol DNA was mixed with DNA from different rice tissues collected from healthy Zerawchanica karatals (ZK) or Tainung 67 (TNG67) seedlings. (a) 3 days post $\mathrm{dH}_{2} \mathrm{O}$ treatment; (b) 7 days post $\mathrm{dH}_{2} \mathrm{O}$ treatment. The linear regression equations and their coefficient of determination $\left(R^{2}\right)$ values are shown on the graph.

Additional file 11: Fig. S4. Transcriptome profiles in Fusarium fujikuroiinoculated Zerawchanica karatals (ZK) and Tainung 67 (TNG67). (a) Principal component analysis (PCA) for the RNA-seq samples. Mock: $\mathrm{dH}_{2} \mathrm{O}$-treated; Ff: F. fujikuroi-inoculated; 1: pooled sample from independent trial 1; 2: pooled sample from independent trial 2. (b) Numbers of differentially expressed genes (DEGs) in the two cultivars. (c) Heat map of the expression levels (log2 fold change) of DEGs. Red represents upregulation and blue represents down-regulation in Fusarium fujikuroi-inoculated plants.

\section{Abbreviations}

ABA: Abscisic acid; ACC: 1-aminocyclo-propane-1-carboxylic acid; ANOVA: Analysis of variance; Ct: Cycle threshold;

CTAB: Cetyltrimethylammonium bromide; DAMPs: Damage-associated molecular patterns; DEGs: Differentially expressed genes; DPI: Days post inoculation; DSI: Disease severity index; EF1a: Elongation factor 1-alpha; ERFs: Ethylene response factors; FDR: False discovery rate; GA: Gibberellin; GO: Gene ontology; HDA: Histone deacetylase; JA: Jasmonic acid; JAZ: Jasmonate ZIM-domain; MAP3K: Mitogen-activated protein kinase kinase kinase; MeJA: Methyl jasmonate; NPR: Non-expressor of pathogenesis-related gene; PAL: Phenylalanine ammonia-lyase gene; PAMPs: Pathogen-associated molecular patterns; PDA: Potato dextrose agar; POEl: Pollen Ole e I; PRRs: Pattern-recognition receptors; PTI: Pattern-triggered immunity; qPCR: Real-time quantitative PCR; qRT-PCR: Real-time quantitative reverse transcription PCR; QTL: Quantitative trait locus; RDP1: Rice diversity panel 1; RRSV: Rice ragged stunt virus; SA: Salicylic acid; TFs: Transcription factors; WAK: Wall-associated kinase; WPI: Weeks post inoculation

\section{Acknowledgements}

We acknowledge Dr. Chi-Yu Chen (National Chung-Hsing University, Taiwan) for providing the F. fujikuroi isolate and Mr. Han-Hui Huang (Taiwan Agricultural Research Institute, Taiwan) for help with the inoculation trials. We thank Dr. Hsin-Hung Yeh (Agricultural Biotechnology Research Center, Academia Sinica, Taiwan) for providing miscellaneous resources and advising on qRTPCR assays. We thank Mr. Hsin-Han Lee for support with transcriptome analysis

\section{Authors' Contributions}

APC, SYC and CLC designed the experiments, analyzed the data, and drafted the manuscript. APC, SYC, MHL, DHW, and CYC performed the experiments.
APC and SSL conducted transcriptome analysis. The authors read and approved the final manuscript.

\section{Funding}

The study was supported by the Ministry of Science and Technology of Taiwan (105-2313-B-002-014-; 106-2313-B-002-021-MY3).

\section{Availability of Data and Materials}

RNA-seq data were deposited in the NCBI Sequence Read Archive database (SAMN13972374 to SAMN13972381). Other datasets used and analyzed during the current study are available from the corresponding author on reasonable request.

Ethics Approval and Consent to Participate

Not applicable.

\section{Consent for Publication}

Not applicable.

\section{Competing Interests}

The authors declare that they have no competing interests.

\section{Author details}

${ }^{1}$ Department of Plant Pathology and Microbiology, National Taiwan University, No. 1, Sec. 4, Roosevelt Rd, Taipei City 10617, Taiwan. ${ }^{2}$ Crop Science Division, Taiwan Agricultural Research Institute, No. 189, Zhongzheng Rd., Wufeng Dist, Taichung City 41362, Taiwan. ${ }^{3}$ Department of Agronomy, National Chung Hsing University, No. 145, Xingda Rd., South Dist, Taichung City 40227, Taiwan. ${ }^{4}$ Institute of Biotechnology, National Taiwan University, No. 1, Sec. 4, Roosevelt Rd, Taipei City 10617, Taiwan.

Received: 14 February 2020 Accepted: 2 September 2020

Published online: 10 September 2020

\section{References}

Agrawal GK, Rakwal R, Jwa NS (2000) Rice (Oryza sativa L.) OsPR1b gene is phytohormonally regulated in close interaction with light signals. Biochem Biophys Res Commun 278:290-298

Agrawal GK, Rakwal R, Jwa NS, Agrawal VP (2001) Signalling molecules and blast pathogen attack activates rice OsPR1 $a$ and OSPR1b genes: a model illustrating components participating during defence/stress response. J Plant Biochem Physiol 39:1095-1103

Anders S, Huber W (2010) Differential expression analysis for sequence count data. Genome Biol 11:R106

Azizi P, Rafii M, Abdullah S, Nejat N, Maziah M, Hanafi M, Latif M, Sahebi M (2016) Toward understanding of rice innate immunity against Magnaporthe oryzae. Crit Rev Biotechnol 36:165-174

Carneiro GA, Matić S, Ortu G, Garibaldi A, Spadaro D, Gullino ML (2017) Development and validation of a TaqMan real-time PCR assay for the specific detection and quantification of Fusarium fujikuroi in rice plants and seeds. Phytopathology 107:885-892

Chen SY, Huang KJ, Kuo YF, Lai MH, Chen YC, Chung CL (2015) Three modified methods for evaluation of bakanae disease resistance in rice seedlings. Plant Pathol Bull 24:201-210

Chen SY, Lai MH, Tung CW, Wu DH, Chang FY, Lin TC, Chung CL (2019) Genomewide association mapping of gene loci affecting disease resistance in the rice-Fusarium fujikuroi pathosystem. Rice 12:85

Chen X, Chen H, Yuan JS, Köllner TG, Chen Y, Guo Y, Zhuang X, Chen X, Zhang YJ, Fu J, Nebenführ A, Guo Z, F. C (2018) The rice terpene synthase gene OsTPS19 functions as an (S)-limonene synthase in planta, and its overexpression leads to enhanced resistance to the blast fungus Magnaporthe oryzae. Plant Biotechnol J 16:1778-1787

Chen X, Ronald PC (2011) Innate immunity in rice. Trends Plant Sci 16:451-459

Chen YC, Lai MH, Wu CY, Lin TC, Cheng AH, Yang CC, Wu HY, Chu SC, Kuo CC, Wu YF, Lin GC, Tseng MN, Tsai YC, Lin CC, Chen CY, Huang JW, Lin HA, Chung CL (2016) The genetic structure, virulence, and fungicide sensitivity of Fusarium fujikuroi in Taiwan. Phytopathology 106:624-635

Chen Z, Gao T, Liang S, Liu K, Zhou M, Chen C (2014) Molecular mechanism of resistance of Fusarium fujikuroi to benzimidazole fungicides. FEMS Microbiol Lett 357:77-84 
Cheng Z, Sun L, Qi T, Zhang B, Peng W, Liu Y, Xie D (2011) The bHLH transcription factor MYC3 interacts with the jasmonate ZIM-domain proteins to mediate jasmonate response in Arabidopsis. Mol Plant 4:279-288

Cheon KS, Jeong YM, Lee YY, Oh J, Kang DY, Oh H, Kim SL, Kim N, Lee E, Baek J, Choi I, Kim KH, Won Y, Yoon I, Cho YI, Han JH, Ji H (2019) Kompetitive allelespecific PCR marker development and quantitative trait locus mapping for bakanae disease resistance in Korean japonica rice varieties. Plant Breed Biotech 7:208-219

Chu SC, Jiang MS, Chan CY, Huang TC (2010) Survey of bakanae disease incidence of rice plants in Taitung area and the improvement of its control measures. Res Bull Taitung Dist Agric Res Ext Stn 20:57-69

Chujo T, Miyamoto K, Shimogawa T, Shimizu T, Otake Y, Yokotani N, Nishizawa Y, Shibuya N, Nojiri H, Yamane H, Minami E, Okada K (2013) OsWRKY28, a PAMP-responsive transrepressor, negatively regulates innate immune responses in rice against rice blast fungus. Plant Mol Biol 82(1):23-37

Chung CL, Huang KJ, Chen SY, Lai MH, Chen YC, Kuo YF (2016) Detecting Bakanae disease in rice seedlings by machine vision. Comput Electron Agric 121:404-411

Croft D, Mundo AF, Haw R, Milacic M, Weiser J, Wu G, Caudy M, Garapati P, Gillespie M, Kamdar MR, Jassal B, Jupe S, Matthews L, May B, Palatnik S, Rothfels K, Shamovsky V, Song H, Williams M, D'Eustachio P (2013) The Reactome pathway knowledgebase. Nucleic Acids Res 42:D472-D477

De Vleesschauwer D, Seifi HS, Filipe O, Haeck A, Huu SN, Demeestere K, Höfte M (2016) The DELLA protein SLR1 integrates and amplifies salicylic acid-and jasmonic acid-dependent innate immunity in rice. Plant Physiol 170:18311847

D'Maris Amick Dempsey AC, Vlot MCW, Daniel FK (2011) Salicylic acid biosynthesis and metabolism. Arabidopsis book/American Society Plant Biologists 9:e0156

Dong J, Chen C, Chen Z (2003) Expression profiles of the Arabidopsis WRKY gene superfamily during plant defense response. Plant Mol Biol 51:21-37

Dong X (2004) NPR1, all things considered. Curr Opin Plant Biol 7:547-552

Doyle JJ, Doyle JL (1987) A rapid DNA isolation procedure for small quantities of fresh leaf tissue. Phytochem Bull 19:11-15

Du Z, Zhou X, Ling Y, Zhang Z, Su Z (2010) agriGO: a GO analysis toolkit for the agricultural community. Nucleic Acids Res 38:W64-W70

El Oirdi M, El Rahman TA, Rigano L, El Hadrami A, Rodriguez MC, Daayf F, Vojnov A, Bouarab K (2011) Botrytis cinerea manipulates the antagonistic effects between immune pathways to promote disease development in tomato. Plant Cell 23:2405-2421

Fabregat A, Jupe S, Matthews L, Sidiropoulos K, Gillespie M, Garapati P, Haw R, Jassal B, Korninger F, May B, Milacic M, Roca C, Rothfels K, Sevilla C Shamovsky V, Shorser S, Varusai T, Viteri G, Weiser J, D'Eustachio P (2017) The reactome pathway knowledgebase. Nucleic Acids Res 46:D649-D655

Fernández-Calvo P, Chini A, Fernández-Barbero G, Chico J-M, Gimenez-Ibanez S, Geerinck J, Eeckhout D, Schweizer F, Godoy M, Franco-Zorrilla JM, Pauwels L, Witters E, Puga M, Paz-Ares J, Goossens A, Reymond P, De Jaeger G, Solano R (2011) The Arabidopsis bHLH transcription factors MYC3 and MYC4 are targets of JAZ repressors and act additively with MYC2 in the activation of jasmonate responses. Plant Cell 23:701-715

Fiyaz RA, Krishnan SG, Rajashekara H, Yadav AK, Bashyal B, Bhowmick P, Singh N, Prabhu K, Singh A (2014) Development of high throughput screening protocol and identification of novel sources of resistance against bakanae disease in rice (Oryza sativa L.). Indian J Genet 74:414-422

Fiyaz RA, Yadav AK, Krishnan SG, Ellur RK, Bashyal BM, Grover N, Bhowmick PK Nagarajan M, Vinod KK, Singh NK, Prabhu KV, Singh AK (2016) Mapping quantitative trait loci responsible for resistance to Bakanae disease in rice. Rice 9:45-45

Gupta A, Solanki I, Bashyal B, Singh Y, Srivastava K (2015) Bakanae of rice-an emerging disease in Asia. J Anim Plant Sci 25:1499-1514

Han X, Kahmann R (2019) Manipulation of phytohormone pathways by effectors of filamentous plant pathogens. Front Plant Sci 10:822

Haq M, Mia MT, Rabbi M, Ali M (2010) Incidence and severity of rice diseases and insect pests in relation to climate change. In: Climate change and food security in South Asia. Springer Netherlands, South Asia, pp 445-457

Hur YJ, Lee SB, Kim TH, Kwon T, Lee JH, Shin DJ, Park SK, Hwang UH, Cho JH, Yoon YN, Yeo US, Song YC, Kwak DY, Nam MH, Park DS (2015) Mapping of qBK1, a major QTL for bakanae disease resistance in rice. Mol Breed 35:78

Jain P, Singh PK, Kapoor R, Khanna A, Solanke AU, Krishnan SG, Singh AK, Sharma $V$, Sharma TR (2017) Understanding host-pathogen interactions with expression profiling of NILs carrying rice-blast resistance Pi9 gene. Front Plant Sci 8:93

Jaiti F, Verdeil JL, Hadrami I (2009) Effect of jasmonic acid on the induction of polyphenoloxidase and peroxidase activities in relation to date palm resistance against Fusarium oxysporum f. sp. albedinis. Physiol Mol Plant Pathol 74:84-90

Ji H, Gheysen G, Ullah C, Verbeek R, Shang C, De Vleesschauwer D, Höfte M, Kyndt $T$ (2015) The role of thionins in rice defence against root pathogens. Mol Plant Pathol 16:870-881

Ji H, Kim TH, Lee GS, Kang HJ, Lee SB, Suh SC, Kim SL, Choi I, Baek J, Kim KH (2018a) Mapping of a major quantitative trait locus for bakanae disease resistance in rice by genome resequencing. Mol Genet Genomics 293:579586

Ji Z, Wang C, Zhao K (2018b) Rice routes of countering Xanthomonas oryzae. Int J Mol Sci 19:3008

Ji Z, Zeng Y, Liang Y, Qian Q, Yang C (2016) Transcriptomic dissection of the rice-Fusarium fujikuroi interaction by RNA-Seq. Euphytica 211:123-137

Ji Z, Zeng Y, Liang Y, Qian Q, Yang C (2019) Proteomic dissection of the riceFusarium fujikuroi interaction and the correlation between the proteome and transcriptome under disease stress. BMC Genomics 20:91.

Jiang Y, Bao L, Jeong SY, Kim SK, Xu C, Li X, Zhang Q (2012) XIAO is involved in the control of organ size by contributing to the regulation of signaling and homeostasis of brassinosteroids and cell cycling in rice. Plant J 70:398-408

Jin J, He K, Tang X, Li Z, Lv L, Zhao Y, Luo J, Gao G (2015) An Arabidopsis transcriptional regulatory map reveals distinct functional and evolutionary features of novel transcription factors. Mol Biol Evol 32:1767-1773

Jin J, Tian F, Yang DC, Meng YQ, Kong L, Luo J, Gao G (2017) PlantTFDB 4.0: toward a central hub for transcription factors and regulatory interactions in plants. Nucleic Acids Res 45:D1040-D1045

Jin J, Zhang H, Kong L, Gao G, Luo J (2013) PlantTFDB 3.0: a portal for the functional and evolutionary study of plant transcription factors. Nucleic Acids Res 42:D1182-D1187

Kang DY, Cheon KS, Oh J, Oh H, Kim SL, Kim N, Lee E, Choi I, Baek J, Kim KH, Chung NJ, Ji H (2019) Rice genome resequencing reveals a major quantitative trait locus for resistance to bakanae disease caused by Fusarium fujikuroi. Int J Mol Sci 20:2598

Kersey PJ, Allen JE, Allot A, Barba M, Boddu S, Bolt BJ, Carvalho-Silva D, Christensen M, Davis P, Grabmueller C, Kumar N, Liu Z, Maurel T, Moore B, McDowall MD, Maheswari U, Naamati G, Newman V, Ong CK, Paulini M, Pedro H, Perry E, Russell M, Sparrow H, Tapanari E, Taylor K, Vullo A, Williams G, Zadissia A, Olson A, Stein J, Wei S, Tello-Ruiz M, Ware D, Luciani A, Potter S, Finn RD, Urban M, Hammond-Kosack KE, Bolser DM, De Silva N, Howe KL, Langridge N, Maslen G, Staines DM, A. Y (2017) Ensembl genomes 2018: an integrated omics infrastructure for non-vertebrate species. Nucleic Acids Res 46:D802-D808

Khan J, Jamil F, Gill M (2000) Screening of rice varieties/lines against bakanae and bacterial leaf blight (BLB). PAK J Phytopathol 12:6-11

Kim BR, Hahm SS, Nam YG (2015) Occurrence of the rice bakanae disease in Chungnam province. Res Plant Dis 21:154-154

Kim MH, Hur YJ, Lee SB, Kwon T, Hwang UH, Park SK, Yoon YN, Lee JH, Cho JH, Shin D, Kim T, Han SI, Yeo US, Song YC, Nam MH, Park DS (2014) Large-scale screening of rice accessions to evaluate resistance to bakanae disease. J Gen Plant Pathol 80:408-414

Kim SH, Park MR, Kim YC, Lee SW, Choi BR, Lee SW, Kim IS (2010) Degradation of prochloraz by rice bakanae disease pathogen Fusarium fujikuroi with differing sensitivity: a possible explanation for resistance mechanism. J Korean Soc Appl Biol Chem 53:433-439

Konan YKF, Kouassi KM, Kouakou KL, Koffi E, Kouassi KN, Sekou D, Kone M, Kouakou TH (2014) Effect of methyl jasmonate on phytoalexins biosynthesis and induced disease resistance to Fusarium oxysporum $\mathrm{f}$. sp. vasinfectum in cotton (Gossypium hirsutum L.). Int J Agron 2014:11

Ku YS, Sintaha M, Cheung MY, Lam HM (2018) Plant hormone signaling crosstalks between biotic and abiotic stress responses. Int J Mol Sci 19:3206

Kyndt T, Nahar K, Haeck A, Verbeek R, Demeestere K, Gheysen G (2017) Interplay between carotenoids, abscisic acid and jasmonate guides the compatible rice-Meloidogyne graminicola interaction. Front Plant Sci 8:951

Langmead B, Salzberg SL (2012) Fast gapped-read alignment with bowtie 2. Nat Methods 9:357

Latchman DS (1997) Transcription factors: an overview. Int J Biochem Cell Biol 29: 1305-1312 
Lee HI, León J, Raskin I (1995) Biosynthesis and metabolism of salicylic acid. Proc Natl Acad Sci 92:4076-4079

Lee MW, Qi M, Yang Y (2001) A novel jasmonic acid-inducible rice myb gene associates with fungal infection and host cell death. Mol Plant Microbe Interact 14:527-535

Lee SB, Hur YJ, Cho JH, Lee JH, Kim TH, Cho SM, Song YC, Seo YS, Lee J, Ts K, Park YJ, Oh MK, Park DS (2018) Molecular mapping of $q B K 1^{W D}$, a major QTL for bakanae disease resistance in rice. Rice 11:3

Lee SB, Kim N, Hur YJ, Cho SM, Kim TH, Lee JY, Cho JH, Lee JH, Song YC, Seo YS, Ko JM, Park DS (2019) Fine mapping of qBK1, a major QTL for bakanae disease resistance in rice. Rice 12:36

Li X, Yang DL, Sun L, Li Q, Mao B, He Z (2016) The systemic acquired resistance regulator OsNPR1 attenuates growth by repressing auxin signaling through promoting IAA-amido synthase expression. Plant Physiol 172:546-558

Liu D, Chen X, Liu J, Ye J, Guo Z (2012) The rice ERF transcription factor OsERF922 negatively regulates resistance to Magnaporthe oryzae and salt tolerance. J Exp Bot 63:3899-3911

Liu LYD, Tseng HI, Lin CP, Lin YY, Huang YH, Huang CK, Chang TH, Lin SS (2014) High-throughput transcriptome analysis of the leafy flower transition of Catharanthus roseus induced by peanut witches'-broom phytoplasma infection. Plant Cell Physiol 55:942-957

Liu W, Liu J, Ning Y, Ding B, Wang X, Wang Z, Wang GL (2013) Recent progress in understanding PAMP-and effector-triggered immunity against the rice blast fungus Magnaporthe oryzae. Mol Plant 6:605-620

Liu X, Bai X, Wang X, Chu C (2007) OsWRKY71, a rice transcription factor, is involved in rice defense response. J Plant Physiol 164:969-979

Livak KJ, Schmittgen TD (2001) Analysis of relative gene expression data using real-time quantitative $P C R$ and the $2^{-\Delta \Delta C T}$ method. Methods 25:402-408

Long JA, Ohno C, Smith ZR, Meyerowitz EM (2006) TOPLESS regulates apical embryonic fate in Arabidopsis. Science 312:1520-1523

Ma LJ, Geiser DM, Proctor RH, Rooney AP, O'Donnell K, Trail F, Gardiner DM, Manners JM, Kazan K (2013) Fusarium pathogenomics. Annu Rev Microbiol 67:399-416

Macho AP, Zipfel C (2014) Plant PRRs and the activation of innate immune signaling. Mol Cell 54:263-272

Makandar R, Nalam V, Chaturvedi R, Jeannotte R, Sparks AA, Shah J (2010) Involvement of salicylate and jasmonate signaling pathways in Arabidopsis interaction with Fusarium graminearum. Mol Plant Microbe Interact 23:861870

Manosalva PM, Davidson RM, Liu B, Zhu X, Hulbert SH, Leung H, Leach JE (2009) A germin-like protein gene family functions as a complex quantitative trait locus conferring broad-spectrum disease resistance in rice. Plant Physiol 149: 286-296

Matić S, Bagnaresi P, Biselli C, Carneiro GA, Siciliano I, Valé G, Gullino ML, Spadaro D (2016) Comparative transcriptome profiling of resistant and susceptible rice genotypes in response to the seedborne pathogen Fusarium fujikuroi. BMC Genomics 17:608

Monaghan J, Zipfel C (2012) Plant pattern recognition receptor complexes at the plasma membrane. Curr Opin Plant Biol 15:349-357

Müller M, Munné-Bosch S (2015) Ethylene response factors: a key regulatory hub in hormone and stress signaling. Plant Physiol 169:32-41

Nahar K, Kyndt T, De Vleesschauwer D, Höfte M, Gheysen G (2011) The jasmonate pathway is a key player in systemically induced defense against root knot nematodes in rice. Plant Physiol 157:305-316

Nakano T, Suzuki K, Fujimura T, Shinshi H (2006) Genome-wide analysis of the ERF gene family in Arabidopsis and rice. Plant Physiol 140:411-432

Nasir F, Tian L, Chang C, Li X, Gao Y, Tran LSP, Tian C (2018) Current understanding of pattern-triggered immunity and hormone-mediated defense in rice (Oryza sativa) in response to Magnaporthe oryzae infection. Semin Cell Dev Biol 83:95-105

Navarro L, Bari R, Achard P, Lisón P, Nemri A, Harberd NP, Jones JD (2008) DELLAs control plant immune responses by modulating the balance of jasmonic acid and salicylic acid signaling. Curr Biol 18:650-655

Ou SH (1985) Rice diseases, 2nd edn. Commonwealth Mycological Institute, Kew

Patkar RN, Benke PI, Qu Z, Chen YY, Yang F, Swarup S, Naqvi NI (2015) A fungal monooxygenase-derived jasmonate attenuates host innate immunity. Nat Chem Biol 11:733

Phukan UJ, Jeena GS, Shukla RK (2016) WRKY transcription factors: molecular regulation and stress responses in plants. Front Plant Sci 7:760
Santiago-Sotelo P, Ramirez-Prado J (2012) prfectBLAST: a platform-independent portable front end for the command terminal BLAST+ stand-alone suite. Biotech 53:299

Sathe AP, Su X, Chen Z, Chen T, Wei X, Tang S, Zhang XB, Wu J (2019) Identification and characterization of a spotted-leaf mutant sp/40 with enhanced bacterial blight resistance in rice. Rice 12:68

Shimono M, Sugano S, Nakayama A, Jiang CJ, Ono K, Toki S, Takatsuji H (2007) Rice WRKY45 plays a crucial role in benzothiadiazole-inducible blast resistance. Plant Cell 19:2064-2076

Siciliano I, Amaral Carneiro G, Spadaro D, Garibaldi A, Gullino ML (2015) Jasmonic acid, abscisic acid, and salicylic acid are involved in the phytoalexin responses of rice to Fusarium fujikuroi, a high gibberellin producer pathogen. J Agric Food Chem 63:8134-8142

Sun D, Lu X, Hu Y, Li W, Hong K, Mo Y, Cahill DM, Xie J (2013) Methyl jasmonate induced defense responses increase resistance to Fusarium oxysporum f. sp. cubense race 4 in banana. Sci Hortic 164:484-491

Tanaka S, Han X, Kahmann R (2015) Microbial effectors target multiple steps in the salicylic acid production and signaling pathway. Front Plant Sci 6:349

Tezuka D, Kawamata A, Kato H, Saburi W, Mori H, Imai R (2019) The rice ethylene response factor OsERF83 positively regulates disease resistance to Magnaporthe oryzae. Plant Physiol Biochem 135:263-271

Thaler JS, Owen B, Higgins VJ (2004) The role of the jasmonate response in plant susceptibility to diverse pathogens with a range of lifestyles. Plant Physiol 135:530-538

Thatcher LF, Manners JM, Kazan K (2009) Fusarium oxysporum hijacks COI1mediated jasmonate signaling to promote disease development in Arabidopsis. Plant J 58:927-939

Thimm O, Bläsing O, Gibon Y, Nagel A, Meyer S, Krüger P, Selbig J, Müller LA, Rhee SY, Stitt M (2004) MAPMAN: a user-driven tool to display genomics data sets onto diagrams of metabolic pathways and other biological processes. Plant J 37:914-939

Tian T, Liu Y, Yan H, You Q, Yi X, Du Z, Xu W, Su Z (2017) agriGO v2.0: a GO analysis toolkit for the agricultural community, 2017 update. Nucleic Acids Res 45:W122-W129

Untergasser A, Cutcutache I, Koressaar T, Ye J, Faircloth BC, Remm M, Rozen SG (2012) Primer3 - new capabilities and interfaces. Nucleic Acids Res 40:e115e115

Volante A, Tondelli A, Aragona M, Valente MT, Biselli C, Desiderio F, Bagnaresi P, Matic S, Gullino ML, Infantino A, Spadaro D, Valè G (2017) Identification of bakanae disease resistance loci in japonica rice through genome wide association study. Rice 10:29

White FF, Yang B (2009) Host and pathogen factors controlling the riceXanthomonas oryzae interaction. Plant Physiol 150:1677-1686

Wu K, Zhang L, Zhou C, Yu CW, Chaikam V (2008) HDA6 is required for jasmonate response, senescence and flowering in Arabidopsis. J Exp Bot 59: 225-234

Yang C, Guo L, Li X, Ji Z, Ma L, Qian Q (2006) Analysis of QTLs for resistance to rice bakanae disease. Chin J Rice Sci 6:657-659

Yuan Y, Zhong S, Li Q, Zhu Z, Lou Y, Wang L, Wang J, Wang M, Li Q, Yang D, He $Z$ (2007) Functional analysis of rice NPR1-like genes reveals that OSNPR1/NH1 is the rice orthologue conferring disease resistance with enhanced herbivore susceptibility. Plant Biotechnol J 5:313-324

Zhang C, Ding Z, Wu K, Yang L, Li Y, Yang Z, Shi S, Liu X, Zhao S, Yang Z, Wang Y, Zheng L, Wei J, Zhenguo D, Zhang A, Miao H, Liu Y, Wu Z, Wu J (2016) Suppression of jasmonic acid-mediated defense by viral-inducible microRNA319 facilitates virus infection in rice. Mol Plant 9:1302-1314

Zhang L, Zhang F, Melotto M, Yao J, He SY (2017) Jasmonate signaling and manipulation by pathogens and insects. J Exp Bot 68:1371-1385

Zhang ZL, Shin M, Zou X, Huang J, Ho TH, Shen QJ (2009) A negative regulator encoded by a rice WRKY gene represses both abscisic acid and gibberellins signaling in aleurone cells. Plant Mol Biol 70:139-151

Zipfel C (2014) Plant pattern-recognition receptors. Trends Immunol 35:345-351

\section{Publisher's Note}

Springer Nature remains neutral with regard to jurisdictional claims in published maps and institutional affiliations. 